\title{
The Prevalence, Causes And Effects Of Drug Use And Abuse On Performance Indicators Among Secondary School Students In Teso South Constituency, Kenya
}

\author{
Etyang Marygoretty, PhD \\ Winga Maureen Adhiambo, PhD \\ Maseno University, Kenya
}

Doi:10.19044/esj.2021.v17n15p111

Submitted: 25 January 2021

Accepted: 03 March 2021

Published: 31 May 2021
Copyright 2021 Author(s)

Under Creative Commons BY-NC-ND

4.0 OPEN ACCESS

Cite As:

Marygoretty E. \& Adhiambo W.M. (2021). The Prevalence, Causes And Effects Of Drug Use And Abuse On Performance Indicators Among Secondary School Students In Teso South Constituency, Kenya.

European Scientific Journal, ESJ, 17(15), 111. https://doi.org/10.19044/esj.2021.v17n15p111

\section{Abstract}

The use of drugs has become more rampant today than at any other time. In learning institutions, especially secondary schools, the use of drugs has resulted in poor concentration in classwork, high rate of absenteeism and failure in exams leading to poor academic performance. The purpose of this study therefore was to: establish the prevalence of drug use among students in Teso South Constituency, establish the causes of drug use and identify the effects of drug use on academic performance indicators among secondary school students in Teso South Constituency. The constituency has a total of 25 public secondary schools with a total of 8023 students. Krejcie and Morgan's formula was used to select 192 students and data was collected from the field using questionnaires and later analyzed using percentages. Results indicate that $54.7 \%, 22.4 \%, 6.7 \%, 4.7 \% 4.2 \%, 3.1 \%$ of the students use Tobacco, Miraa, Cocaine, Tranquilizers, Kuber and Marijuana respectively. Also, the most influential causes of drug abuse among them were Peer influence at $90.1 \%$, family background at $57.1 \%$ and availability of drugs at $30.8 \%$. Lastly, $89.6 \%$ of the students had poor grades due to drug abuse alongside $78.6 \%$ of them affected by low concentration span and lack of interest in studies. The study, therefore, inferred that there is a high of drug ab prevalence use amongst secondary school students with family, peers as well as availability contributing to the onset of drug abuse. 
The study concluded that drug abuse interferes with academic performance indicators of secondary school students in Teso South Constituency.

Keywords: Drug Use, Drug Abuse, Academic Performance Indicators, Secondary School Students

\section{Introduction}

There is an overwhelming outcry throughout the world today over the rapid growth of youths using drugs that the law prohibits. Drugs are chemical substances that modify mental, emotional and behavioral functioning (Goode, 1989). The extent of drug use has been identified as one of the greatest problems in educational institutions. This impacts the various aspects of learning such as students' discipline and interest in learning hence affecting academic performance.

According to the World Drug report (2005), the consumption of illicit drugs has tremendously increased throughout the recent years. The report further states that a major World trend is the increasing availability of many kinds of drugs. A report released by United Nations Drugs Control Programme (2004) indicated clearly that $4.8 \%$ of the global population consumes drugs and alcohol, but the worrying fact is that those hooked are the youth still in secondary schools.

Africa, over the recent years, has experienced a rise in the production, distribution and consumption of drugs among the youth with young adults being the majority victims (Asuni \& Pela, 1986). Among all the continents, it is noted that Africa has a huge percentage of young and vulnerable population which has become the target market for the illicit drug industry. This constitutes $56 \%$ of the population aged between $14-19$ years, which is the age of secondary school going students. In Ethiopia it is reported that $82 \%$ of the street children in Addis Ababa are involved in consumption of one drug or another (United Nations, 2013).

According to the United Nations (UN) (2013) statistics, 37,000 people in Africa die annually from diseases associated with drug abuse and the UN also estimates that there are 28 million drug users in Africa. An International conference on drug abuse in Kampala in 2013 reported that young people in high drug consumption countries were the most vulnerable section of the population, especially those in the period of early and late adolescence who are mostly unable to resist peer pressure and prone to experimenting with drugs in schools or even outside school.

In Kenya, a report by NACADA (2010) posits that drug and alcohol use has become prevalent more than at any other time. The report adds that majority of the users are students in secondary schools, tertiary colleges and 
universities. In the past, the actual existence of drug use as a social problem was rare because of strong social structures. Notably, the low levels or nonexistence of drug use was sustained as a result of strong kinship ties that ran through different social institutions in Africa. This was enhanced by the traditions and taboos which were upheld to discourage the misuse of drugs. With the weakening of the traditional fabric of the society, drug abuse has permeated the education sector in a detrimental way.

Subsequently, drug misuse and abuse has consequential repercussions such as failure to keep up with the academic responsibilities. According to The National Institute on Alcohol and Alcoholism (2005) the United States of America has about 25\% of students experiencing difficulty in academics due to drug use. Such difficulties include earning low grades, doing poorly on tests, missing class and falling behind in academic performance. Even students who do not use drugs may suffer academically as a result of their peers taking drugs. Conclusively, drug abuse undermines the academic mission of schools, colleges and universities. Drug use and its effect on students' performance can, therefore, lead to a decline in the overall academic performance of students and as a result, schools may face declining student retention rates and end up with poor reputation.

\section{Statement of the Problem}

There has been a significant drop in the academic performance among secondary school students in Teso South Constituency in recent years. For the last 3 years, less than $20 \%$ of the students enrolled for K.C.S.E examination in this constituency have secured admission to the public and private universities. This has raised a lot of concern among the education stakeholders. As previous literature intimates, drug and alcohol abuse are among the major factors leading to poor academic performance among secondary school students. Therefore, this study seeks to investigate the influence of drug use on academic performance indicators among secondary school students in Teso South constituency.

The study objectives were to:

1. Establish the prevalence of drug abuse among secondary school students of Teso South Constituency

2. Establish the causes of drug abuse among secondary school students in Teso South Constituency

3. Identify the effects of drug use on academic performance indicators among secondary school students Teso South Constituency 


\section{Prevalence of Drug Abuse}

The World Health Organization (WHO) (2004) has given a worldwide global status report on alcohol and drug consumption. It gave an estimated figure of two billion people who were involved in drug consumption. Similarly, a report released by United Nations Drugs Control Programme (2004) expressed that $4.8 \%$ of the global population consume drugs, but the worrying fact is that those hooked are the youth. For instance, in America, the prevalence of drinking is $39.7 \%$ among $12-20$ year olds while 7.0 million people (18.5\%) in the12-20 age bracket reported drinking alcohol in the past one month (NSDUH, 2019).

In Africa, the survey conducted in Zambia revealed overwhelming evidence indicating the extensive consumption of alcohol. According to the Zambia Demographic Health Survey report (2008), it was revealed that 76\% of men and women consume alcohol. The authors of the survey report noted that alcohol consumption varies with age and gender. From a different perspective, in Egypt, drug abuse, in particular heroine, is becoming a serious problem where around $6 \%$ of sampled secondary school students admitted to have experimented with drugs. Umaru, Sambo and Abdulwahid (2014) in their study in Nigeria also pointed out that one third of the students were smoking cigarettes while in Kenya today drug use has become prevalent than at any other times (NACADA, 2010). NACADA (2010) report adds that majority of the drug users are students in secondary schools, tertiary colleges and universities. Moreover, the report alludes that the use of the drugs has spread at a fast rate and reached every part of the country with the report showing that $5.3 \%$ of females and $22 \%$ of males aged between $15-19$ years are involved in drug abuse.

According to a National Baseline survey carried out by the NACADA (2012) and the Ministry of Education (MOEST) (2012), drugs and substances used for the first time by students in both primary and secondary schools across the Country include: Cigarettes and Bhang (4-20\%), Miraa / Khat (7$30 \%)$, Kuber 6\%, Cocaine and Heroin (2-3\%). Data gathered from teachers in some selected schools indicate that learners carry alcoholic spirits, sometimes mixed with fruit juices, sweets, glucose, ice cream, tea and other drugs to school. This is taken during their free time or in between lessons, hence a generally drunken student body (MOEST, 2015).

A study done in sections of Murang'a and Kajiado Counties revealed an average prevalence of current alcohol abuse among high -school students at 37\% with Murang'a having a prevalence of $38 \%$ while Kajiado had 36\% (Okwarah, 2017). Other studies that were conducted by Adan (2016) and Birhanu, Bisetegne and Woldeyohannes (2014) also pointed out that students consumed Miraa Alcohol, cigarretes, marijuana, cocaine amphetamines, glue, mandrax, inhalants and methaqualone. 
These related previous literature sets the stage for a need to ascertain whether drug abuse could be the major factor affecting student academic performance in Teso South Constituency. Data on substance abuse amongst secondary school students should be collected every so often so as to determine trends of commonly abused drugs in a place such as Teso South Constituency, hence the need for this study.

\section{Causes of Drug Abuse amongst Students}

The causes of drug abuse can be at an individual, interpersonal, institutional, community and societal levels (Adan, 2016). When properly investigated, these causes can give an indication as to why a certain individual got involved in the use or abuse of drugs. The individual causes include personal characteristics like one's age, sex, level of education and knowledge (Tarter et al, 2003), which is also linked to an individual's inherited genetic aspects from parents with alcohol use problems (Kendler et al, 2000). It also includes aspects such as hostility, low self-esteem and difficulties in controlling impulsive behavior (Walton \& Roberts, 2004).

The second level is the interpersonal domain which is linked with the adolescent's social interactions with friends, family and close relations. This also involves poor early childhood upbringing in the family due to poor family life circumstances (Barret \& Turner, 2005). It also includes low parental discipline and poor parental monitoring. The third level of causes of drug abuse is the institutional level. At this level the school culture is the main factor that influences secondary school students' involvement in drug abuse.

The fourth level is the external environmental factors that may influence drinking. These include the availability of affordable alcohol and the concentration of drinking outlets in the area surrounding the school. In a place or country where the laws or regulations are relaxed the problem of alcohol use may continue. According to Spooner (2009), the above domains or levels do not operate in isolation. They are interrelated and their combination makes the drug abuse problem among adolescents a more complex one.

According to Birhanu et al (2014) who conducted their study in Ethiopia, substance abuse is correlated with poor academic performance, low perceived risk of substances and friends use of substances. In a related study Adan (2016) in a study of Drug abuse among secondary school students in Wajir Kenya, found that drug abuse was caused by peer pressure, lack of discipline, parental encouragement, lack of school policies on drug abuse and lack of parental guidance on drug abuse. These are key instances that provides 
the dire need to apply the same investigative approach in Teso South constituency.

\section{Effects of drug abuse on students' academic performance}

Good academic performance always depends on a healthy mind and body. It is important therefore that the brain be in good working condition all the time. Drugs, especially addictive ones, affect the brain and nervous system as a whole. According to, National Institute on Alcohol and Alcoholism (2005) in United State of America about 25\% of students experience difficulty in academics due to drug use. Such difficulties include earning low grades, doing poorly on tests, missing class and falling behind in academic performance.

In Africa, drug trafficking and consumption among students accounts for $26 \%$ of global participation (UNODC, 2004). There are secondary effects of drug abuse which include taking care of friends on drugs and being victims of assault which can affect school work of students who don't use drugs. These consequences can have dramatic end results. Subsequently, school administrators report that significant number of students who drop out of school do so because drugs interfere with their academics (Birhanu et al., 2014).

According to MOEST (2015) report, Kenya’s Busia County has seven constituencies with the rate of drug and alcohol abuse quite alarming. Nambale constituency which is the neighbouring constituency to Teso South records averagely $10 \%$ of the students in form three and four as victims of drug abuse. The report adds that the academic performance in secondary level of schools within Busia county is generally above average, with many students scoring a $\mathrm{C}$ and above, except in Teso South Constituency, where $75 \%$ of the students in secondary school score above $\mathrm{C}$, therefore recording a $60 \%$ failure. In Teso South constituency, the situation of drug abuse among secondary school students is the same. Gross impairment and decline in academic performance as a result of drug use is becoming rampant.

It is noted that drugs reduce number of hours a learner spends in studies (NACADA, 2012). Poor academic performance among secondary school students in this constituency has several indicators such as students failing in test, being absent in class, dropping out of school and poor grades. The student involved in drug abuse may, therefore, not reach her/his full potential and may use drugs later in life. It is believed that students who use drugs are likely to perform poorly. Furthermore, no research has ever been carried out on effects of drug abuse on academic performance indicators among secondary school students in Teso South Constituency, hence the need of this study. 


\section{Methods}

\section{Research Design}

Descriptive survey method was used in this study. This type of research design is useful when collecting information about people's attitudes, habits and opinions (Orodho, 2009). According to Mugenda and Mugenda (1999) the descriptive survey design is the best method available to social scientists who are interested in collecting original data for the purposes of describing a population which is too large to observe directly. Both quantitative and qualitative techniques of data collection were used in the study.

\section{Study Area}

This research was conducted in Teso South Constituency, one of the seven constituencies in Busia County. Teso South Constituency covers an area of 299.6 square kilometers. It is mainly occupied by the Iteso community, one of the plain Nilotic ethnic groups in Kenya. Teso South Constituency experiences a cool climate with an average temperature of $22^{\circ} \mathrm{C}$ and rainfall of $750 \mathrm{~mm}-1800 \mathrm{~mm}$ annually, the soil here is loam black and fertile; hence the main economic activity here is Agriculture, KNBS, (2015). The area recorded perennial poor performance in KCSE exams in Busia County in recent years.

\section{Target Population}

Since the focus of this study was to investigate the trend of drug abuse by school going adolescents, the study population consisted of 25 public secondary schools. The target population of 8023 students were from those schools.

\section{Sample and Sampling Procedure}

Krejcie and Morgan's (1970) formula was used to get a sample size of 192 students. Simple random sampling was used to select the 192 students.

\section{Research instruments}

The researchers used questionnaires for data collection. The questionnaires were administered to the students which enabled the researchers to collect large amounts of data at once (See Appendix 1).

\section{Pilot study}

Before visiting the sampled schools for data collection, the researcher conducted a pre-testing of the questionnaires using two schools in the Constituency which were not part of the final sample. The aim of the pilot study was to not only to determine accuracy, clarity and suitability of the research instrument but also to check its validity. 


\section{Validity and Reliability of instruments}

Validity is the degree to which results obtained from the data analysis actually represent the phenomenon under study. Content validity was ascertained with the help of the supervisor. Reliability refers to a measure of the degree to which a research instrument yields consistent results or data after repeated trials (Mugenda \& Mugenda, 2009). Test retest was conducted, getting a reliability co efficient of 0.70 on the research instruments.

\section{Data collection procedure}

Questionnaires were prepared and distributed to the sampled 192 students. The questionnaires were collected immediately on completion. The collected data was then stored for analysis. The questionnaires did not have any slot for the name to assure anonymity in the sourcing of information as well as to maintain high sense of integrity.

\section{Data Analysis Procedure}

Once data was obtained from the field it was arranged and grouped according to relevant research questions, then summarized using frequencies, and percentages. This was done with the help of SPSS software.

\section{Ethical considerations}

Ethical issues are an integral part of the research planning and implementation process. Ethics in research refers to a code of conduct or expected social norm of behaviour while conducting research. The researcher ensured great care was taken to protect the research participants. In the first place, the full purpose of the research was explained to the participants, allowing them to choose whether to participate or not. Participants were assured of confidentiality of all that they would report in the study.

\section{Results}

Table 1. Prevalence of drug abuse in secondary schools in Teso South Constituency

\begin{tabular}{|l|l|l|l|}
\hline Commonly abused drugs by students & Frequency & Percentage \\
\hline Alcohol & 105 & 54.7 \\
\hline Miraa & 13 & 6.7 \\
\hline Marijuana & 6 & 3.1 \\
\hline Cocaine & 9 & 4.7 \\
\hline Tranquilizers & 8 & 4.2 \\
\hline Kuber & 8 & 4.2 \\
\hline Tobacco & 43 & 22.4 \\
\hline Total & $\mathbf{1 9 2}$ & $\mathbf{1 0 0 . 0}$ \\
\hline
\end{tabular}


From Table 1 it is evident that there is high rate of drug abuse among students in Teso South Constituency. 54.7\% of the students take alcohol while $22.4 \%$ take tobacco. From the table it is evident that students in Teso South Constituency have engaged in consuming seven different types of drugs. This shows that they abuse a wide variety of drugs. These results are in agreement with NSDUH (2019) who also found prevalence rates of alcohol use of 39.7\% among 12-20 year olds. The prevalence rates are also in agreement with MOEST (2012) who found that cigarettes and Bhang were smoked by $4-20 \%$, miraa was chewed by $7-30 \%$, Kuber $6 \%$ and cocaine and heroin 2-3\%. With regard to the variety of drugs, these results are in agreement with Birhanu et al. (2014) who also found that students consumed miraa, alcohol, cigarettes, marijuana and cocaine.

Table 2. Factors that cause the students to abuse drugs

\begin{tabular}{|c|c|c|c|c|}
\hline \multirow{2}{*}{$\begin{array}{l}\text { Factors that cause the } \\
\text { students to abuse drugs }\end{array}$} & \multicolumn{2}{|c|}{ Less influential } & \multicolumn{2}{|c|}{ Very influential } \\
\hline & Frequency & Percentage & Frequency & Percentage \\
\hline Mass media & 168 & \multirow{5}{*}{$\begin{array}{l}92.3 \\
42.9 \\
69.2 \\
9.9 \\
97.8\end{array}$} & 14 & $7.7 \%$ \\
\hline Family background & 78 & & 104 & $57.1 \%$ \\
\hline Availability & 126 & & 56 & $30.8 \%$ \\
\hline Peer influence & 18 & & 164 & $90.1 \%$ \\
\hline Others & 178 & & 4 & $2.2 \%$ \\
\hline
\end{tabular}

These study findings summarized in Table 2 indicate that peer influence and family background are the most influential causes of drug abuse among students in Teso South Constituency as expressed by a percentage of $90.1 \%$ and $57.1 \%$ respectively. $30.8 \%$ of the students agreed that availability of drugs exacerbates drug abuse among students while only $7.7 \%$ feel that mass media causes drug abuse among students.

These findings suggest that majority of the students agreed that peer influence, family background and availability of drugs are the leading causes of drug abuse among secondary school students in Teso South Constituency. This is in agreement with the study carried out by NACADA (2012) on rapid assessment of the status of drug and substance abuse in Kenya, which established that peer influence and availability of drugs were the major factors fueling drug abuse among the youths in Kenya.

The last objective sought to establish the effects of drug use on performance indicators of students. The students were expected to rank each effect as very severe, moderately severe, less severe or not severe at all. The results are summarized in table 3 : 
Table 3. Effects of drug abuse on the students in secondary schools

\begin{tabular}{|c|c|c|c|c|c|}
\hline & \multicolumn{2}{|c|}{ LESS SEVERE } & \multicolumn{2}{c|}{ VERY SEVERE } \\
\cline { 2 - 3 } $\begin{array}{c}\text { Poor relationship with } \\
\text { others }\end{array}$ & 165 & $90.7 \%$ & & Frequency & Percentage \\
\hline Low concentration span & 39 & $21.4 \%$ & 17 & $9.3 \%$ \\
\hline Poor grades & 19 & $10.4 \%$ & & 143 & $78.6 \%$ \\
\hline School dropouts & 95 & $52.2 \%$ & & 87 & $47.8 \%$ \\
\hline Lack of interest in studies & 44 & $24.2 \%$ & & 138 & $75.8 \%$ \\
\hline
\end{tabular}

The study found out that there was a great effect of drug abuse on students' performance. It is noted that 163 students representing $89.6 \%$ agreed that drug abuse caused poor grades among students in secondary school in Teso South Constituency, in comparison to 19 students representing 10.4\% who disagreed. $78.6 \%$ of the students pointed out that drug abuse affected the students' concentration span in class, leading to a decrease in concentration ability in class. This is quite a high number compared to 39 (21.4\%), who disagreed that there was no effect of drug abuse in students' concentration span in class. These findings are in agreement with the results found by Abot, (2005) who carried out a survey of how drugs affect the students' concentration span, which is further drastically reduced, setting in boredom.

The study also revealed that drug abuse causes lack of interest in studies among students. This is evident from Table 3 which indicates that 138 (75.8\%) students who have abused drugs have experienced a decline of interest in schooling and feel that studies have no meaning in their life. Only $44(24.2 \%)$ students disagreed to this, citing that there was no effect of drug abuse on the students' interest in learning. Also, according to the findings of the study, only 17(9.3\%) agreed that drug abuse had a negative effect on the students' relationship with others compared to 165 (90.7\%) who disagreed that drug use causes poor relationship among students.

Generally, these study findings reveal that there were negative effects of drug abuse on overall academic performance indicators among students in the schools. This is in agreement with United Nations, (2005) view that cognitive and behavioral problems experienced by drug-using youths may interfere with their academic performance and also present obstacles to learning.

\section{Conclusions}

The study concluded that there is a high prevalence of drug abuse amongst secondary school students in Teso South Constituency. It was also noted that family and peers contributed to the onset of drug abuse and that drug abuse interferes with performance indicators of secondary school students. 


\section{Recommendations}

This study avers that the school administration employ measures in line with NACADA recommendations to curb drug abuse in schools. The study recommends that tackling drug abuse requires a three pronged approach whereby the family, peers and the community are all brought on board and that secondary school students focus on their studies and stop abusing drugs.

\section{References:}

1. Abot, I. (2005). Substance Use among Students and Out Of School Youth in Urban Area of Nigeria. W.H.O. Geneva

2. Adan, M. A. (2016). Drug Abuse in Public Secondary Schools: Causes, Effects and Interventions in Wajir East District, Wajir County, Kenya. Unpublished Masters Thesis Kenyatta University.

3. Asuni T. and Pela O. (1986). Drug Abuse in Africa. Bulletin of Narcotics $38(1,2)$ 56-60

4. Barrett A. E., and Turner R. J. (2006). Family Structure and Substance use Problems in Adolescence and early adulthood examining explanations for the relationship. Addiction 101(1) 109-120.

5. Goode, E. (1989) Drugs in American Society. New York McGrawhill.

6. Kenya National Bureau of Statistics, (2015). Kenya National Bureau of Statistics.

7. Kendler K. S., Ohlsson H., Sundquist K., and Sundquist J. (2015). The causes of parent offspring transmission of Drug abuse: A Swedish population based study. Psychol Med 45(1): 87-95

8. Krejcie, R.V., and Morgan, D.W. (1970). Determining sample size for research activities. Educational and Psychological Measurement, 1970 (30), $607-610$.

9. Mugenda, O. M. and Mugenda, A. G. (2009) Research Methods: Qualitative and Quantitative Approaches (Revised edition) Nairobi: Acts Press.

10. MOEST (2012). District Education Officer, Teso South Sub County. Annual report.

11. MOEST (2015). District Education Officer, Teso South Sub County. Annual report.

12. NACADA (2004). Youth in Peril: Alcohol and Drug use in Kenya. Nairobi, NACADA

13. NACADA (2010). Drug and Substance Abuse in Kenya: Nairobi: NACADA.

14. NACADA (2012). Drug and substance abuse: The Kenyan context. Nairobi, NACADA 
15. NSDUH (2019) National Survey on Drug use and Health. Table7.16B - Alcohol use in Lifetime, Past year and Past month among persons aged 12 to 20 by Gender: Percentages, $2002-2019$.

16. Okwarah, P. O. (2017). Prevalence and correlates of alcohol use among underage high-school students in Murang'a and Kajiado Counties, Jomo Kenyatta University of Agriculture and Technology , Juja, Kenya

17. Orodho, J. (2009). Elements of education and social science. Research methods. Kenezja Publishers, Maseno, Kenya.

18. Spooner C. (2009) Causes and correlates of adolescent drug abuse and implications for treatment. Drug and Alcohol Review vol 18, Issue 4 pp 453-475

19. Umaru Y, MIA, O,O, Sambo, S and Abdulwahid, U (2014) The effect of cognitive restructuring intervention on tobacco smoking among adolescents in senior secondary schools in Zaria Kaduna State, Nigeria. European Scientific Journal, ESJ, 10 (5) 327 - 336

20. UNDOC (2004). Global Illicit Drug Trend. New York: United States.

21. United Nations, (2005). World Drug Report. New York: Oxford University Press.

22. United Nations (2013). World Drug Report. New York: Oxford University Press.

23. Walton, K. E., \& Roberts, B. W. (2004). On the relationship between substance use and personality traits: Abstainers are not maladjusted. Journal of Research in Personality, 38(6), 515535. https://doi.org/10.1016/j.jrp.2004.01.002

24. World Drug Report (2005). Drug statistic vol.2. Oxford University Press.

Appendix I: Questionnaire for students

PART A: General Information (Tick using $(\sqrt{ })$ appropriately)

1. What is your gender? Female [ ] Male

2. How old are you? years

3. Have you ever used drugs other than for medical purposes? Yes [ ] No [ ]

4. If yes, for how long have you used them?

1 year [ ] 2-3 years [ ] More than years [ ]

5. What is your parents' education level?

Father

Mother 


\section{PART B:}

6. Commonly abused drugs (Please tick the substances that you have used)
i. Alcohol
ii. Miraa
iii. Marijuana
iv. Cocaine
v. Tranquilizers
vi. Others

\section{vii. None}

7. To what extent did the following factors cause you to abuse drugs?

\begin{tabular}{|c|c|c|c|c|}
\hline Factors & $\begin{array}{c}\text { Very } \\
\text { influential } \\
4\end{array}$ & 3 & $\begin{array}{c}\text { Influential } \\
\text { influential } \\
2\end{array}$ & $\begin{array}{c}\text { Not } \\
\text { influential } \\
1\end{array}$ \\
\hline $\begin{array}{c}\text { Family } \\
\text { background }\end{array}$ & & & & \\
\hline $\begin{array}{c}\text { Availability of } \\
\text { drugs }\end{array}$ & & & & \\
\hline Peer pressure & & & & \\
\hline Frustrations & & & & \\
\hline Mass media & & & & \\
\hline Parents' status & & & & \\
\hline
\end{tabular}

8. How widespread is drug abuse in your school?

9. To what extent do the following effects of drug abuse affect you?

\begin{tabular}{|c|c|c|c|c|}
\hline Effects & Severe & Moderate & $\begin{array}{c}\text { Less } \\
\text { severe }\end{array}$ & $\begin{array}{c}\text { No } \\
\text { effects }\end{array}$ \\
\hline Lack of interest in studying & & & & \\
\hline Low concentration span & & & & \\
\hline $\begin{array}{c}\text { Poor relationship with other } \\
\text { students }\end{array}$ & & & & \\
\hline Poor grades & & & & \\
\hline
\end{tabular}

